\title{
Study of Farm Vehicle Crashes in Delaware
}

\author{
Kasra Karimi' ${ }^{1}$ Ardeshir Faghri', Michael Vaughan² \\ ${ }^{1}$ Department of Civil and Environmental Engineering, University of Delaware, Newark, USA \\ ${ }^{2}$ Office of the Interim Vice Provost for Diversity \& Inclusion, University of Delaware, Newark, USA \\ Email: faghri@udel.edu, vaughan@udel.edu
}

How to cite this paper: Karimi, K., Faghri, A. and Vaughan, M. (2021) Study of Farm Vehicle Crashes in Delaware. Open Journal of Safety Science and Technology, 11, 104-119. https://doi.org/10.4236/ojsst.2021.113008

Received: June 22, 2021

Accepted: August 13, 2021

Published: August 16, 2021

Copyright $\odot 2021$ by author(s) and Scientific Research Publishing Inc. This work is licensed under the Creative Commons Attribution International License (CC BY 4.0).

http://creativecommons.org/licenses/by/4.0/

\begin{abstract}
The increasing number of traffic conflicts between farm vehicles (FVs) and other motorists on public roads has raised safety concerns for Delaware transportation authorities. Farm Vehicle Crashes (FVCs) are less frequent than passenger car, truck, and motorcycle crashes and therefore, have not received proper attention in the past. This study provides a descriptive statistical analysis of FVCs in Delaware between May 2005 and August 2020 to present a better understanding of the characteristics of these crashes. The crash data was extracted from the DelDOT crash database and the State Police Annual Reports. The statistical analysis was performed using MATLAB and crash mapping was performed using ArcGIS Pro. The results show that an average of 14 FVCs occurred each year in this period; however, the annual number of FVCs has been constantly increasing since 2016. The percentage of fatal crashes among FVCs was found to be 3.7 times the state's average for all crashes. Sussex county accounted for nearly half of these crashes. About two-thirds of FVCs took place within the rural boundaries and the rest in urban zip codes. Two peaks were observed throughout the year, one from April to July and another from August to October. The majority of the FVCs occurred during daylight, in clear weather and on a dry surface; however, crashes during dark (not-lighted) conditions were nearly 2.5 times more likely to result in injury than in daylight. Major collectors were associated with the highest risk of FVCs among all function classes. Rollovers and head-on collisions were few in numbers but had the highest percentage of personal injuries. Rear-end collisions, the most common collision type, were found to be overrepresented among crashes under dark (not-lighted) conditions. In conclusion, this study shows that the severity of FVCs is higher than the average for all crashes. Further, the high percentage of rear-end FVCs under dark conditions implies the importance of improving the visibility, lighting, and marking of FVs.
\end{abstract}

\section{Keywords}

Traffic Safety, Farm Vehicle Crashes, Rural Road Safety, Agricultural Equipment on Public Roads 


\section{Introduction}

Agriculture is a major component of Delaware's economy. According to the 2017 Census of Agriculture, over 500,000 acres of land area are used for farming; where, over 6200 Farm Vehicles (FVs) are operating. The fleet of FVs in Delaware consists of tractors (88.8\%), grain and bean combines (10.8\%), and self-propelled forage harvesters (less than $0.4 \%$ ) [1]. In the past few years, during the harvest seasons, DelDOT and the Department of Agriculture have urged drivers to be alert of the presence of agricultural equipment on roads and to practice safe road-sharing techniques when encountering them [2]. Unfortunately, these urgings do not seem to be sufficient for mitigating the issue. The interference between regular traffic with farm vehicle traffic has increased due to the expansion of the urban areas into traditional farming areas. There has been an annual increase in the number of Farm Vehicle Crashes (FVCs) in the past few years.

The number of FVCs is significantly lower than passenger cars, trucks, and other typical road vehicles. This has created a misconception that undermines the importance of this issue. As a result, the safety of farm vehicles on public roads has been overlooked in the past in many aspects including regulations, safety improvement programs, data collection, and research. However, despite the lower number and exposure rate of FVs, they are associated with a high risk of crashes [3]. Further, the severity of FVCs is reported by several studies to be significantly higher than non-farm vehicle crashes [4] [5] [6] [7]. The safety issues associated with the transportation of farm vehicles and equipment on public roads have been investigated by multiple studies in some of the Midwestern and Southern states (e.g. [8]-[15]). This study is intended to provide a better understanding of the characteristics of FVCs in Delaware. For this purpose, road crashes involving farm vehicles were analyzed over a 15-year period. A descriptive statistical analysis is represented to assess different characteristics of the crashes such as time-dependent variables, location, road classification, weather conditions, road surface condition, lighting condition, and the manner of impact are analyzed based upon the frequency and severity of the crashes.

\section{Methods}

The crash data used for this analysis was provided by DelDOT, which included 189 reported crashes involving farm vehicles from May 2005 to August 2020. It should be noted here that the complete record for 2005 was not available in this database. Additionally, from 2005 to 2019, 31 crash cases were identified that appeared in the State Police Annual Reports [16] but were missing in the DelDOT database, including a fatality case in 2006. Since the occurrence year and damage type were the only information presented on the State Police Reports, these 31 cases were only included in analyzing severity and year of the crash. The 189 available records from DelDOT were analyzed for crash characteristics including, crash severity (accident type based on the damage level), county, boundary classification, type of roadway, time of day, month, year, weather conditions, surface condition, lighting condition, and the manner of impact. 


\section{Results and Discussion}

\subsection{Severity (Damage Type)}

The reported crashes were classified into three groups based upon damage type as property damage, personal injury, and fatality. Among the 189 available records of crashes in the DelDOT database, the classification is as follows, $141(74.60 \%)$ property damage, 45 (21.81\%) personal injury, and 3 (1.59\%) fatal crashes. In terms of the number of people involved, 53 people were injured and 4 people died because of FVCs. By adding the 31 records of crashes from the State Police Annual Reports, the percentage of fatality and personal injury cases will increase to $1.81 \%$ and $24 \%$, respectively, which is presented in a pie chart in Figure 1. For comparison purposes, a similar analysis was performed for all crashes in Delaware (including farm and non-farm vehicles) from 2005 to 2019 based upon Delaware's Annual Traffic Statistical Report [16] which is presented in Figure 2. It can be seen that the percentage of personal injury crashes for FVCs is very similar to the overall state average; however, the percentage of fatal crashes is 3.7 times higher than for all crashes. Several studies reported a fatality percentage close to $2 \%$ for FVCs. The percentage of personal injury crashes in Delaware seems to be slightly lower than those reported in Maryland, Iowa, New York, and North Carolina [6] [11] [14] [17].

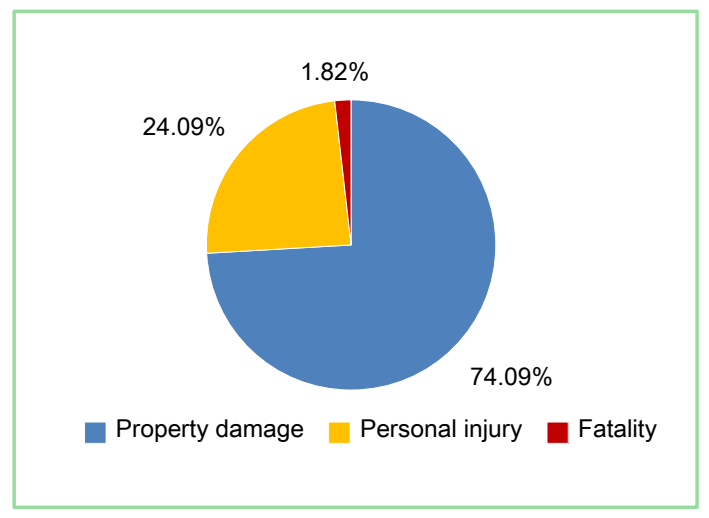

Figure 1. Classification of FVCs in Delaware by severity (2005-2020).

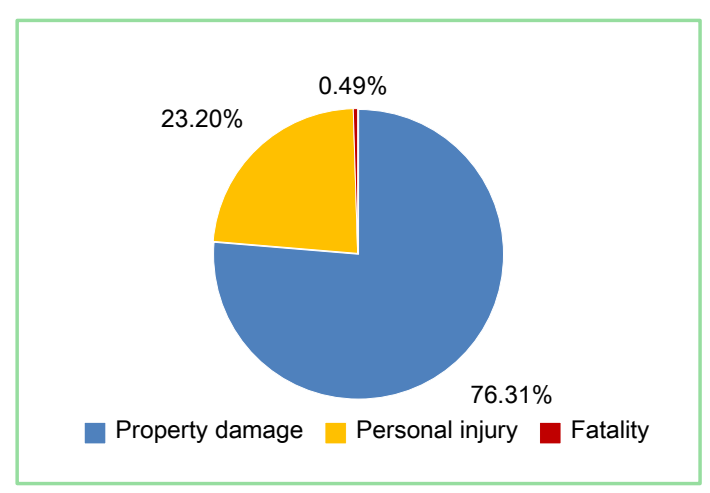

Figure 2. Classification of all crashes in Delaware by severity (2005-2019). 


\subsection{County}

Figure 3 shows the location of FVCs on a map of the State of Delaware with individual county designations. It can be seen that, Sussex County is highest with $53 \%$, followed by Kent County with 27\% and then New Castle County with $20 \%$. The share of each county in FVCs can be partially explained by the number of farm vehicles operating within the county. Figure 4 shows the share of FVCs along with the number of tractors in each county based on the 2017 Census of Agriculture [18]. This comparison shows that the percentage of FVCs for a given county is somewhat proportionate to the number of tractors; however, the share of New Castle county FVCs is slightly higher than its share in the number of tractors which might be attributed to the fact that this county is the most densely populated.

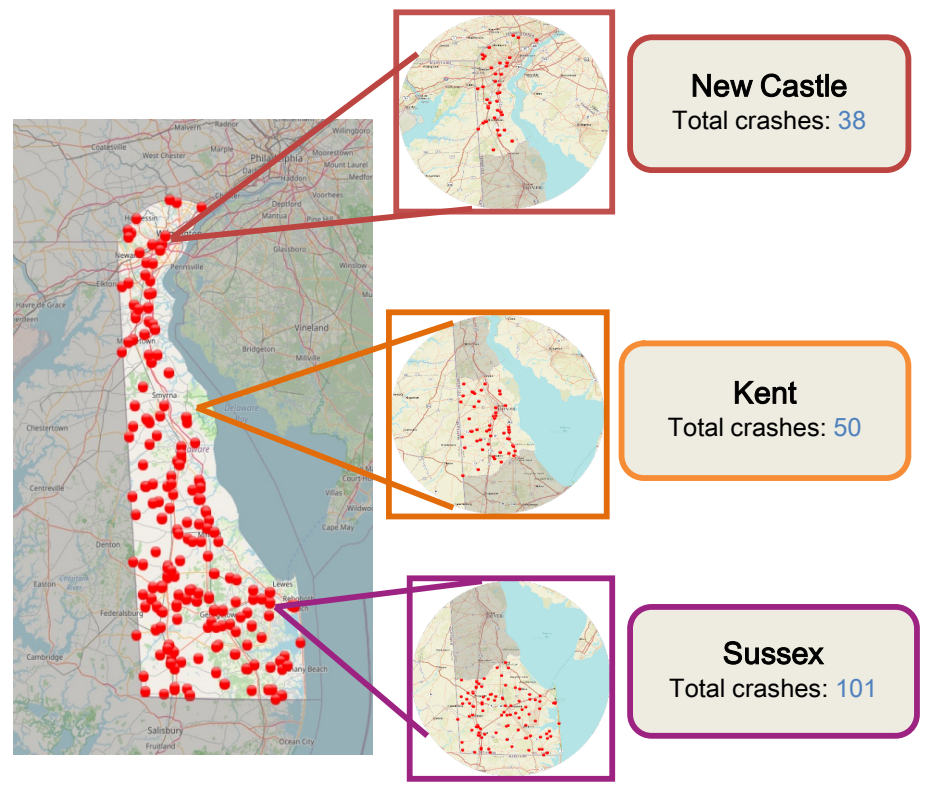

Figure 3. FVCs in Delaware by county.

PERCENTAGE OF FVCS

new Castle $\quad$ Kent $=$ Sussex

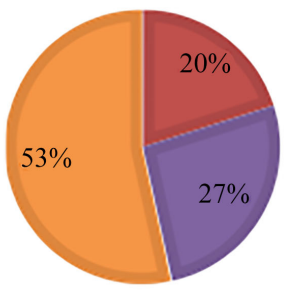

(a)
PERCENTAGE OF TRACTORS

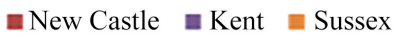

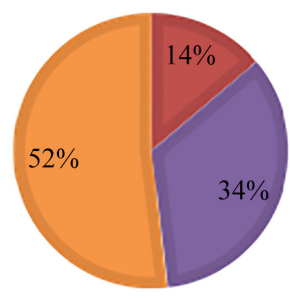

(b)

Figure 4. (a) Percentage of FVCs in Delaware by county; (b) percentage of tractors in Delaware by county based on 2017 Census of Agriculture [18]. 


\subsection{Boundary Classification}

According to the 2010 Census [19], an urbanized area is an area with a population of more than 50,000, and an urban cluster is an area with a population between 2500 and 50,000. Further, a rural area is defined as an area that doesn't fit the definition of an urbanized area or urban cluster. Figure 5(a) shows the percentage of FVCs in Delaware by urbanization boundary, and Figure 5(b) shows the number of crashes in each boundary zone concerning their severity. The result shows that urban crashes account for about one-third (30\%) of all FVCs. This finding is consistent with the findings of [10] which collected the FVCs data from nine Midwestern states. The percentage of fatal and injury crashes for rural areas were $23.5 \%$ and $1.5 \%$, and for urban areas $24.5 \%$ and $1.7 \%$, respectively. The fact that the percentages for rural and urban crashes were very similar was surprising since rural crashes tend to be more severe than urban crashes. According to NHTSA Traffic Safety Facts [20] in 2017, the fatality rate per 100 million vehicle miles traveled at the national level was 2.1 times higher in rural areas than in urban areas and for Delaware, in particular, the fatality rate was 3.3 times higher in rural areas. One possible explanation for that similarity might be the fact that even FVCs that occurred within urban boundaries take place largely in less populated suburbs that have similar traffic characteristics to rural areas.

The location of the urban and rural FVCs is shown on the state map in Figure 6. Urban boundaries are highlighted on the map by a light pink color. Among urban boundaries, Laurel and Middletown had highest number of crashes; however, as both areas are magnified in Figure 6, it can be seen that the density of the crashes at the vicinity of Laurel is higher.

\subsection{Time-Dependent Variables}

In terms of time-dependent variables, the analysis includes the year, month, day of the week, and time of the day. The number of the FVCs in each year is presented in Figure 7 based on both the DelDOT database (May 2005 to August 2020) and the State Police Annual Reports (2005 to 2019). It is shown that some

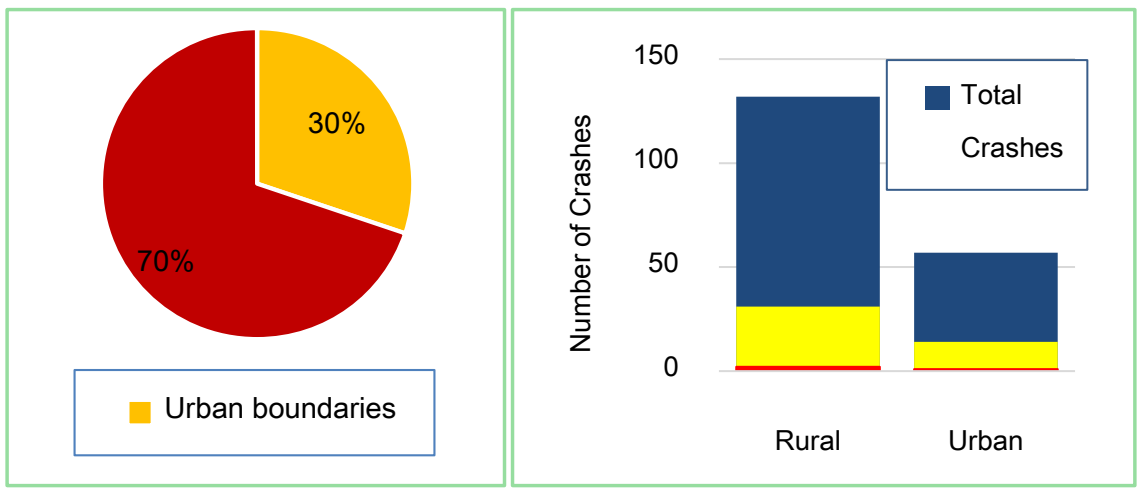

(a)

(b)

Figure 5. FVCs in Delaware by urbanization boundary. (a) The percentage of rural and urban crashes; (b) the number of rural and urban crashes by their severity level. 


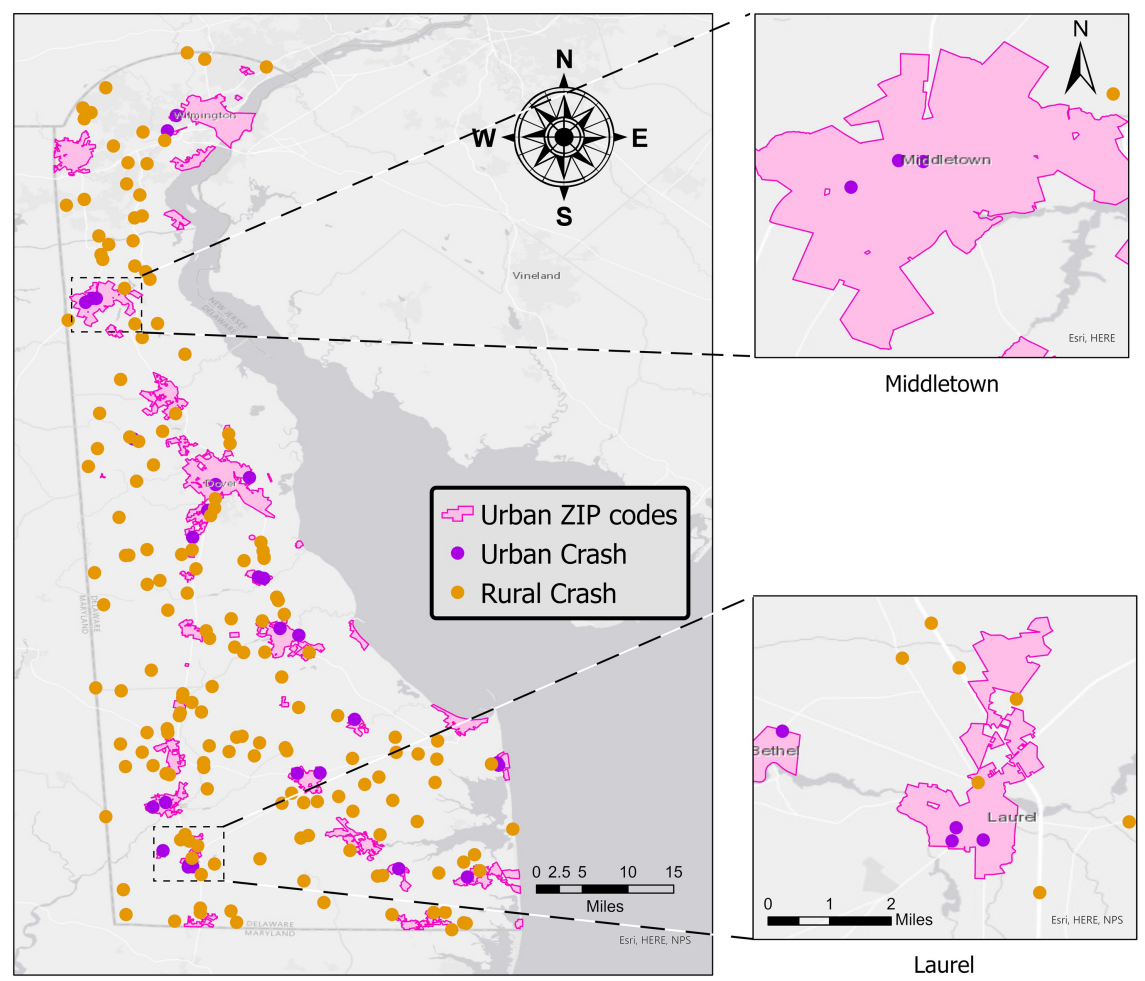

Figure 6. Location of rural and urban FVCs on the state map.

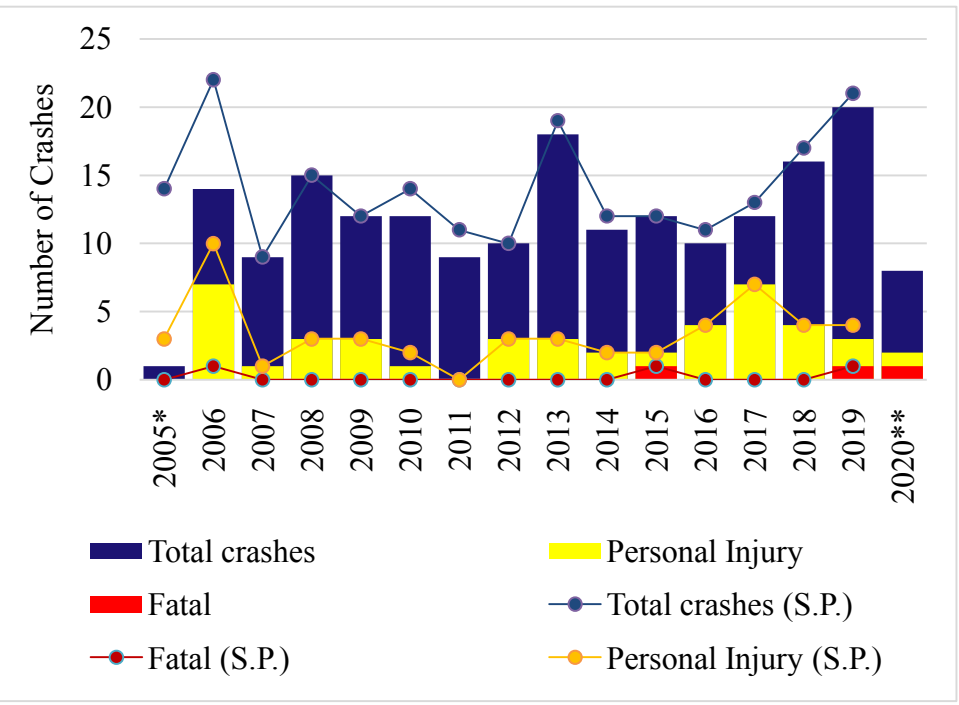

Figure 7. The Number of FVCs in Delaware by year based on the DelDOT database (bars), and State Police (S.P.) annual reports (lines). ${ }^{*}$ for 2005 DelDOT data was incomplete. ${ }^{*}$ for 2020 data was limited to January through August.

crashes are missing from the DelDOT database, and when considering the higher reported numbers, an average of 14 FVCs occurred each year. Although the number of crashes through this period fluctuates substantially absent any notable pattern, a significant upward trend can be seen from 2016 to 2019; where, the number of crashes almost doubled. Moreover, two of the fatality cases happened 
within the past two years.

The frequency of FVCs by month is presented in Figure 8. This chart shows that the number of crashes was lower during winter and spring, and higher during the summer and fall which would be considered as the planting, growing, and harvest seasons for farmers. March and June had the lowest and highest number of FVCs, respectively. Although some studies from other states showed that the number of FVCs was higher during the harvest season, the Delaware peak was experienced during the growing and planting seasons (April to August). The same trend was reported by Hughes and Rodgman [13] in North Carolina. Surprisingly, despite the significant change in the total number of FVCs, the number of injury crashes follows a much flatter trend line and stays close to the average of 4 crashes per month.

Figure 9 shows the distribution of FVCs over days of the week. As shown, most crashes happen during the week with fewer on the weekend, especially Sunday. This can be expected since many farmers take Sunday off and the general traffic volume on the roads is less during the weekends. Crashes are distributed evenly during the weekdays and no meaningful differences were observed.

Figure 10 shows the number of FVCs during different times of the day. The number of crashes increases as the farming day starts around 5:00 AM and reaches its peak at noon, and declines from there and reaching its minimum around midnight. In terms of the severity of the crashes, it can be seen that the peak of personal injury crashes doesn't exactly follow the peak of all crashes and is shifted more towards the darker hours of the day. The median hour for all crashes was noon, while the median for personal injury crashes occurred at 3:00 PM.

\subsection{Lighting Conditions}

Figure 11 represents the number of crashes by the lighting conditions. It appears that the majority of the FVCs (73.5\%) occurred during daylight. This result complies with the studies from other states and in particular the Maryland study [17]. While the number of crashes during dark (not-lighted) conditions was only $17 \%$ of all crashes, the injury percentage for this category was nearly $47 \%$ which is much higher than the $19 \%$ injury percentage for the daylight category. Moreover, two of the three fatal cases happened under dark (not-lighted) conditions and the lighting for the remaining fatal case was unknown.

\subsection{Weather Condition and Road Surface}

Figure 12 and Figure 13 show FVCs by weather and road surface condition. Nearly $80 \%$ of FVCs occurred under clear weather and $14 \%$ under cloudy weather. Snow weather had the highest percentage of injury crashes with $47 \%$, following by cloudy weather (33\%) and clear weather (19\%). About $90 \%$ of crashes took place on a dry surface. This finding is consistent with the finding of other studies and correlates with the fact that farming tasks are most likely to be accomplished during clear weather. 


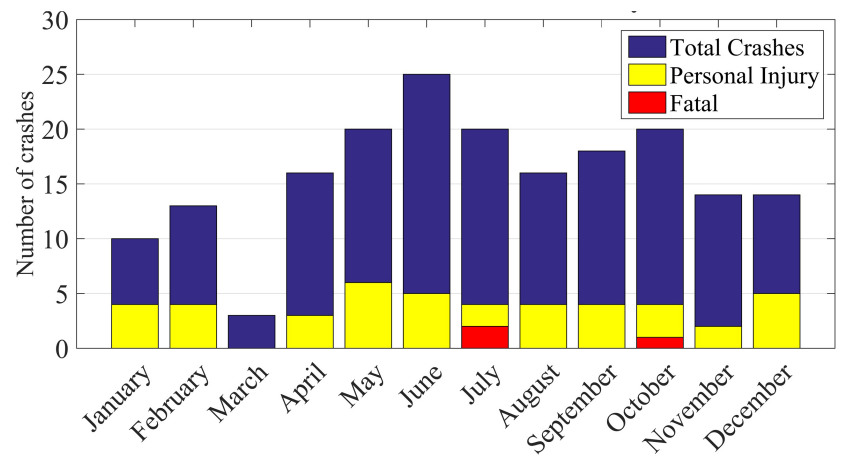

Figure 8. FVCs in Delaware by month.

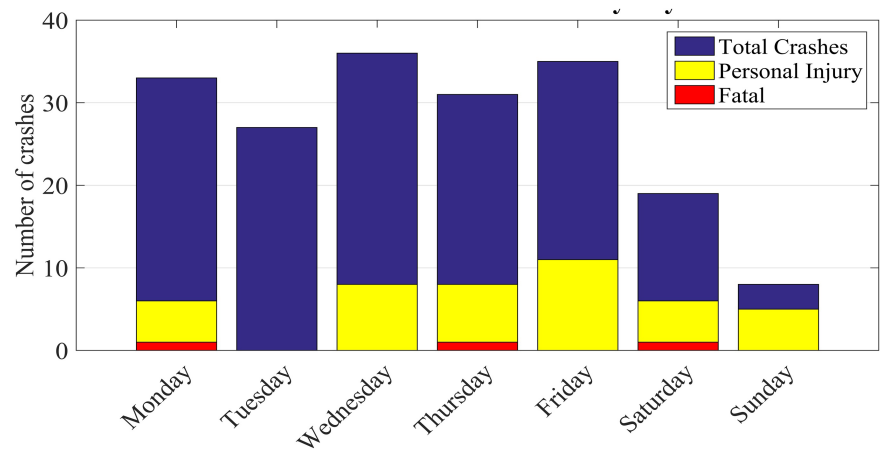

Figure 9. FVCs in Delaware by day of the week.

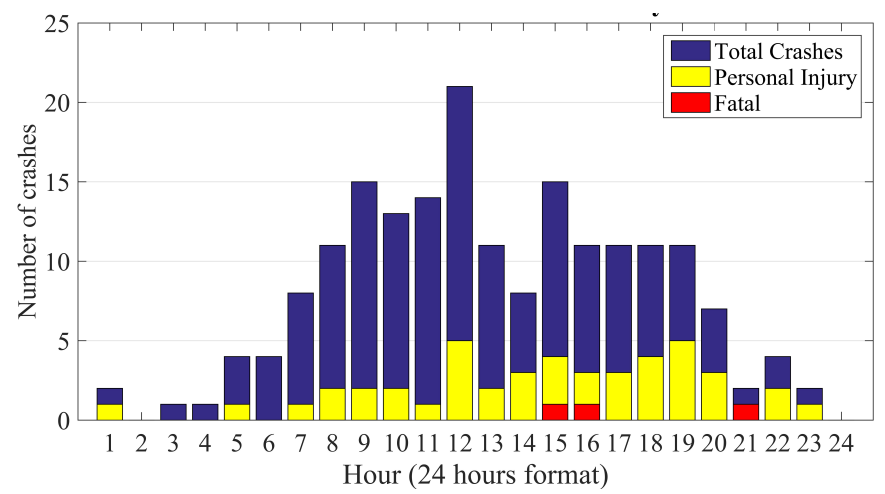

Figure 10. FVCs in Delaware by the time of the day.

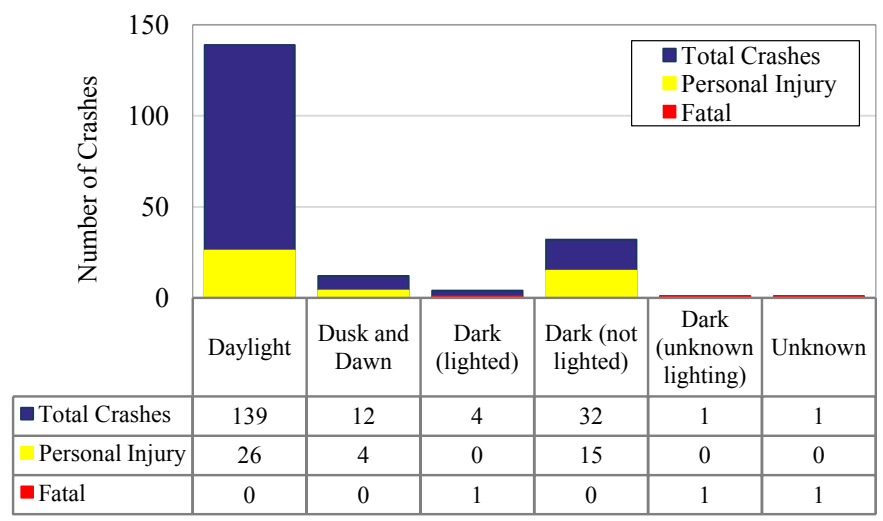

Figure 11. FVCs in Delaware by lighting condition. 


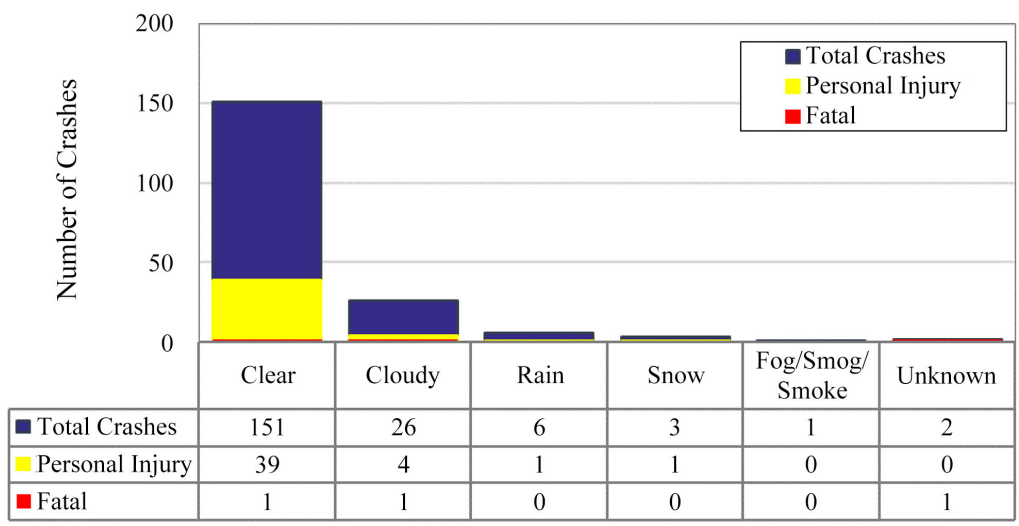

Figure 12. FVCs in Delaware by weather.

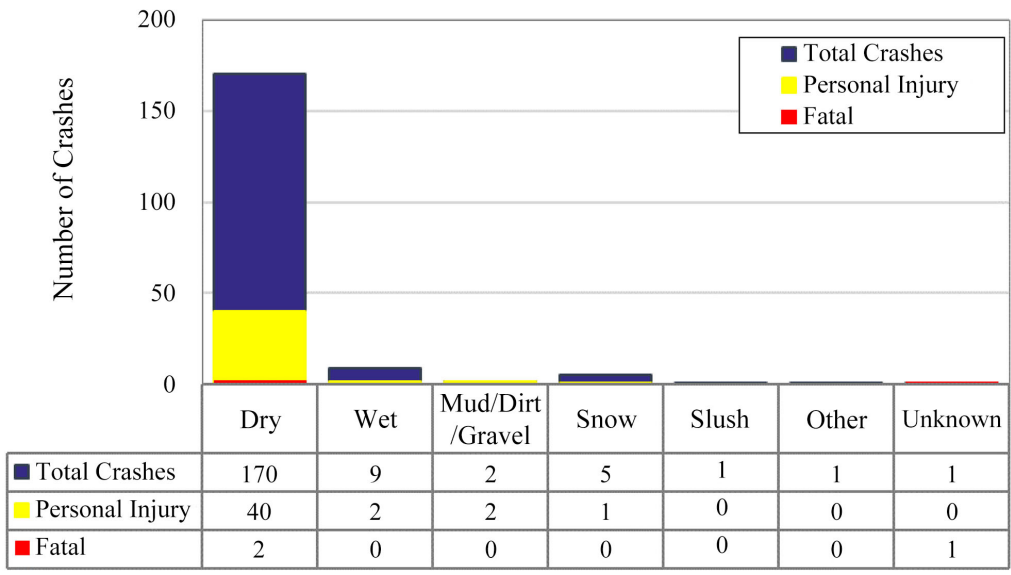

Figure 13. FVCs in Delaware by the surface condition.

\subsection{Road Type}

Figure 14(a) displays the map of Delaware roads based on their functional class defined by DelDOT [21] and Figure 14(b) shows the percentage of each category in the state's total miles of roads. Unfortunately, the functional class of nearly $30 \%$ of the crashes was unknown. Among the known cases, major collectors and local roads account for the majority of the FVCs with $29 \%$ and $21 \%$, respectively, as presented in Figure 15. Considering the low percentage of major collectors of total state's miles of road (7\%), the risk of FVCs in this classification is nearly 14 times that of the local roads. Freeways have the lowest percentage of crashes since they not only comprise $1 \%$ of the total state roads but also slow-moving farm vehicles are not allowed on most high-speed high-volume roads.

Local roads, major and minor collectors were the only categories with fatalities. Among them, minor collectors had an injury percentage of $27 \%$, following by local roads and major collectors with $23 \%$ and $15 \%$, respectively. Figure 16 also shows that the majority of crashes occurred on non-junction segments (76\%) and nearly $16 \%$ either happened at intersections or were intersection-related. Gkritza et al. [11] also reported that the majority of FVCs occurred on non-intersection segments of the road in Iowa. However, it should be noted that multiple factors can 
impact the frequency and severity of crashes in each functional class, such as the speed limit and traffic exposure.

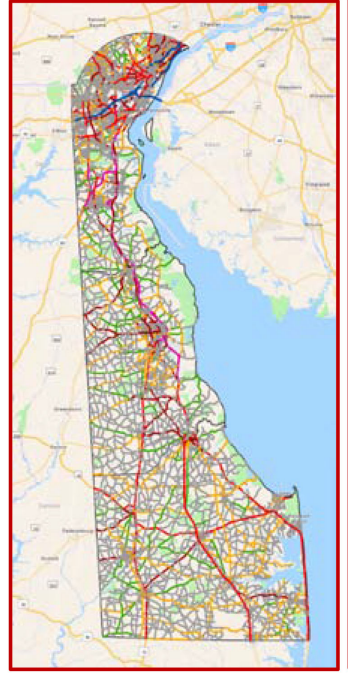

(a)

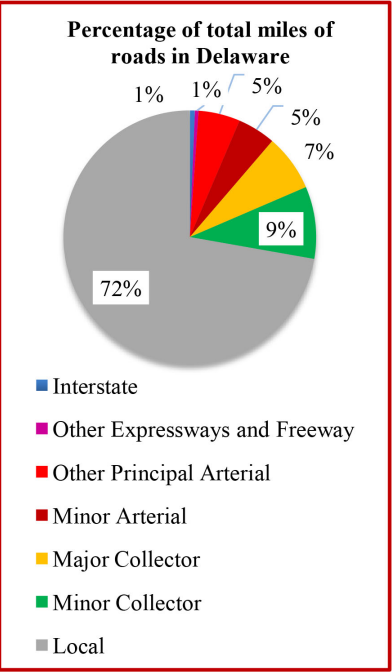

(b)

Figure 14. Mapping (a) and percentage (b) of Delaware's roads by functional classification [21].

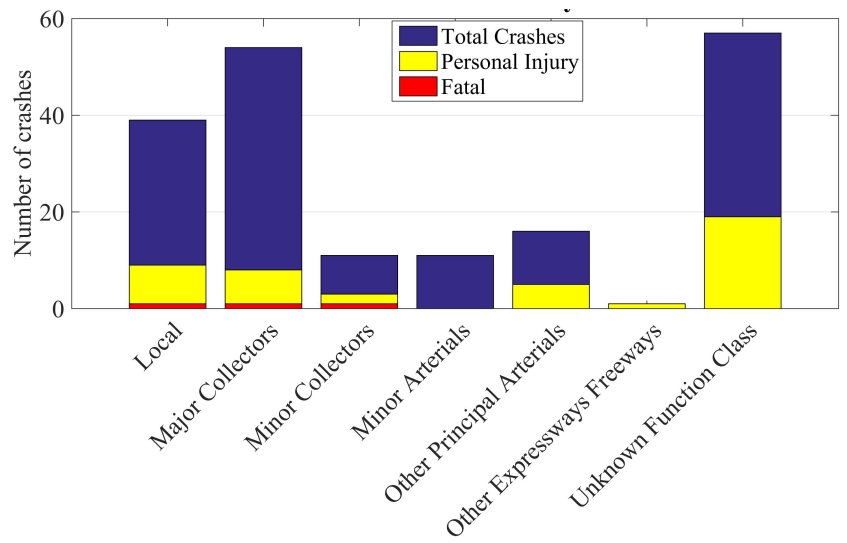

Figure 15. FVCs in Delaware by road functional class.

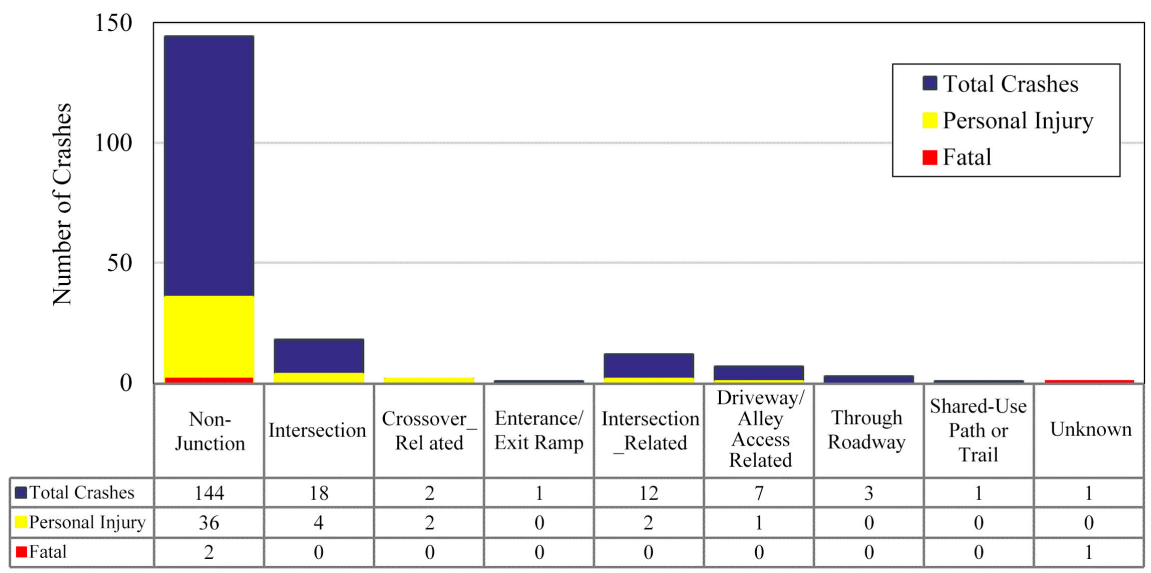

Figure 16. FVCs in Delaware by junction type. 


\subsection{Manner of Impact}

Figure 17 shows the number of FVCs in Delaware by their manner of impact along with the number of fatal and injury crashes, and Figure 18 shows the percentage of each category in a pie chart. By combining the same-direction and opposite-direction sideswipe collisions, four major categories can be seen, each accounting for nearly a quarter of the pie. The most frequent type was front to rear (rear-end) collision which comprised $24 \%$ of all FVCs, followed by angle, single-vehicle, and sideswipe same direction crashes which account for $22 \%, 19 \%$, and $17 \%$ of all crashes, respectively. Sideswipe collisions combined account for $27 \%$ of all crashes. The single-vehicle crashes category includes collision with any other objects (e.g., fixed objects and animals) and accidents such as rollover with only the farm vehicle being involved in the impact; however, other vehicles could contribute indirectly to the crash. Among single-vehicle crashes, rollover only accounted for 4 crashes (2.12\%); however, half of them resulted in personal injuries. Head-on collisions were also few in numbers but had the highest percentage of injury crashes (50\%), followed by rear-end collisions ( $40 \%)$, single-vehicle crashes (25\%), and angle crashes (20\%). The combination of sideswipe collisions had an injury percentage of $12 \%$; however, surprisingly the injury percentage for the same-direction category was three times higher than the opposite-direction.

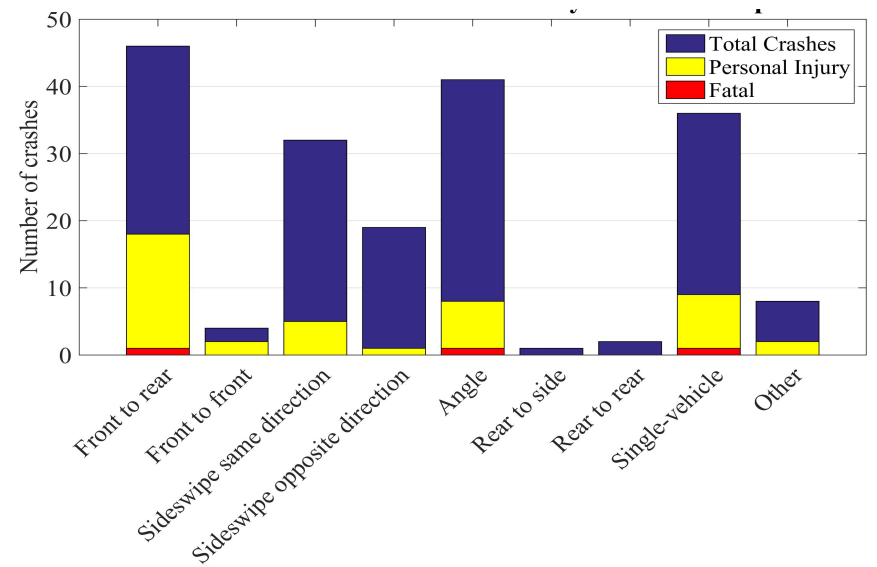

Figure 17. FVCs in Delaware by the manner of impact and their severity.

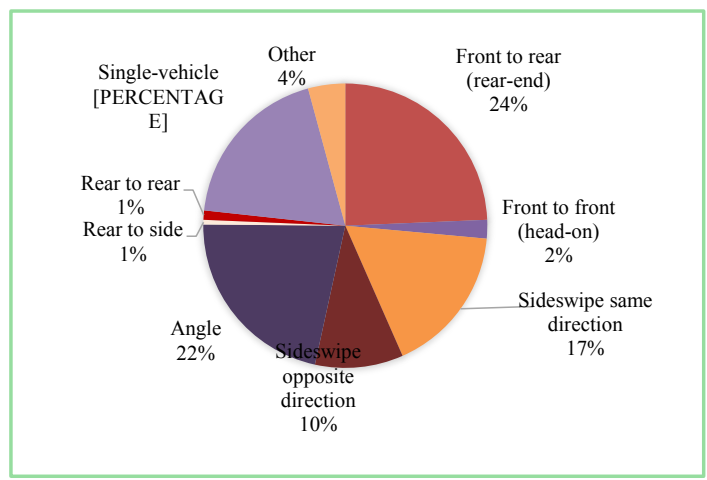

Figure 18. Pie chart demonstration of FVCs in Delaware by the manner of impact. 
In order to assess the possible relationship between lighting conditions and different types of crashes, the manner of collision is analyzed based upon the hour of the day and lighting conditions. Figure 19 depicts the distribution of different manners of collisions throughout the day. To avoid crowding the image, only six of the most important categories are shown here. Furthermore, since similar analysis was conducted by Glascock et al. [15], the hour spans are set according for comparison purposes. The result shows that different crash types can follow different trends throughout the day. The peak of angle crashes occurred between 9:00 AM to 12:00 PM, and after that reduced through the rest of the day. Rear-end collision seems to be the only category that shows a similar trend to the one observed by Glascock et al., which is increased in numbers after 12:00 PM and experiences its peak during the darker hours of the day.

Figure 20 shows the percentage of each crash type for different lighting conditions. Further, this figure shows that all of the head-on collisions occurred in conditions other than daylight. Crashes during daylight conditions belong to the most diverse variety of crash types, while the rear-end crashes have dominated

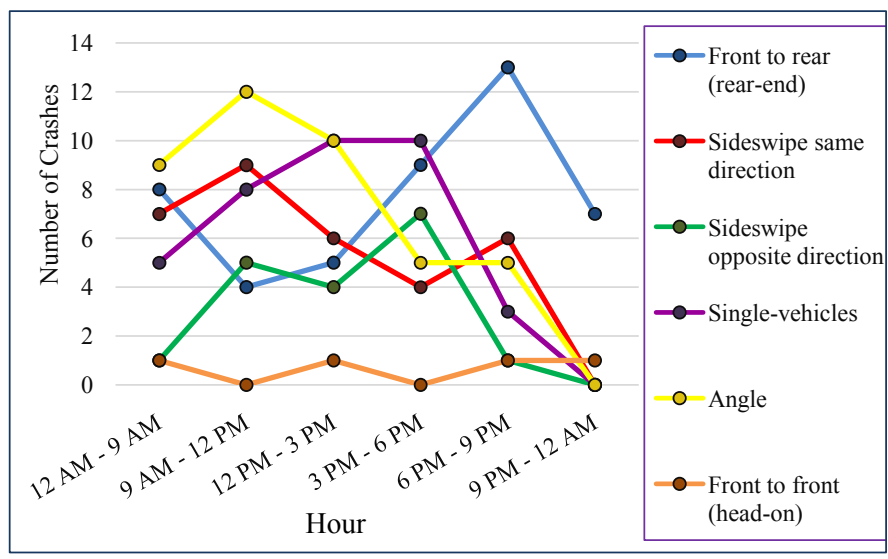

Figure 19. Distribution of FVCs in Delaware throughout the day by the manner of collision.

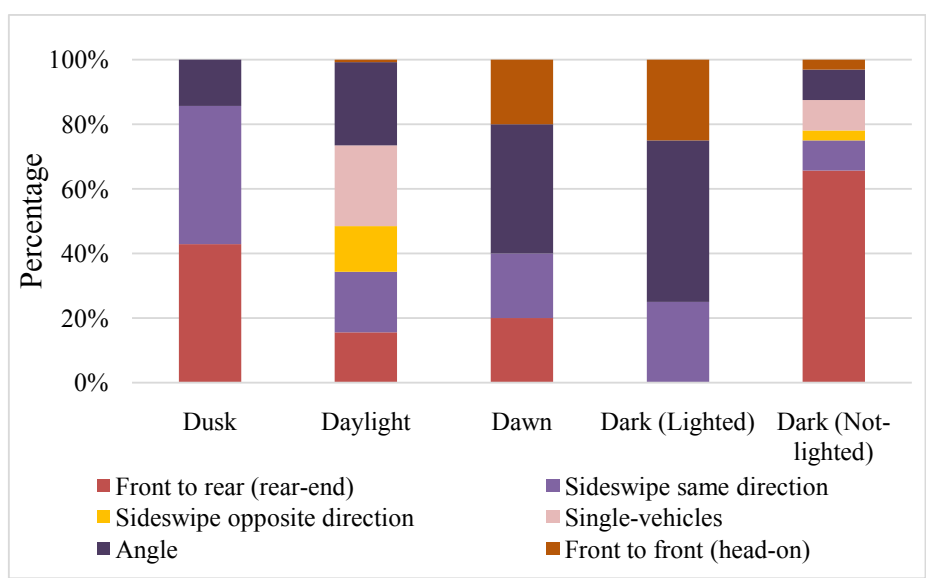

Figure 20. Percentage of FVCs in Delaware by the manner of collision for different lighting conditions. 
the category of the dark (not-lighted) condition. Rear-end crashes comprise about $65 \%$ of crashes under dark conditions while they only account for $15.6 \%$ of crashes under daylight. The overrepresented share of rear-end crashes under dark conditions implies that poor lighting and marking of farm vehicles may be a contributing factor, and improvements in that area can potentially reduce the risk of rear-end crashes.

\section{Conclusions}

Crashes involving farm vehicles in the state of Delaware in a 15 -year period (2005-2020) were analyzed. On average, 14 FVCs occurred each year. Among the 220 available records from the DelDOT database and the State Police Annual Reports, $74 \%$ of crashes resulted only in property damage, $24 \%$ resulted in personal injuries, and $1.82 \%$ resulted in fatalities. The percentage of personal injury crashes was similar to the state average percentage for all crashes, but the percentage of fatal FVCs was found to be 3.7 times higher. The percentage of fatal and personal injury crashes in Delaware was found to be slightly lower than studies from other states.

Sussex County had the highest number of crashes which accounted for over $50 \%$ of all crashes, followed by Kent and Newcastle County, respectively. The percentage of FVCs in each county was found to be largely proportional to their share of farm tractors. About $70 \%$ of the crashes occurred within the rural zip codes while $30 \%$ in urban boundaries. The crash locations seemed to be spread over the state and no cluster of crashes was observed on the map.

The frequency of FVCs has constantly increased since 2016. Two peaks were observed throughout the year, one from April to July, and another from August to October, and fewer crashes occurred between November and March. While it is commonly held that the largest peak occurs during the harvest season, this study demonstrated that the risk of FVCs in Delaware is higher during the planting and growing seasons. The months of June and March had the highest and lowest crashes percentages, respectively. FVCs were less likely to occur during the weekend. The median for all FVCs throughout the day happened at noon while personal injury FVCs occurred later in the afternoon. These data support the premise that the severity of the crashes increases through afternoon and evening, which can partially be associated with the lighting condition.

The majority of the FVCs occurred during daylight, in clear weather, and on a dry surface. This result was expected since these are favorable conditions for farmers and farm vehicles are less likely to operate during dark hours and harsh weather conditions; however, some of the categories with less frequency showed higher injury rates. While crashes under dark (not-lighted) conditions comprised only $17 \%$ of all crashes, the percentage of injury crashes for this category was nearly 2.5 times higher than the daylight category. In terms of weather conditions, snow conditions had the highest rate of injury crashes followed by cloudy and clear conditions, respectively. 
Among the crashes with known functional class, half of the crashes occurred on major collectors and local roads. Considering the fact that major collectors account for $29 \%$ of the crashes while comprising only $7 \%$ of the total miles of state road, they are associated with a high risk of FVCs. In terms of the severity of crashes, minor collectors had the highest percentage of injury crashes with $27 \%$, followed by local roads and major collectors. The majority of crashes occurred on non-junction segments and nearly $16 \%$ either happened at intersections or were intersection-related. It should be noted that for determining the most high-risk locations and segments, other factors such as speed limit and exposure rate for regular traffic and farm vehicles should be considered as well.

The most frequent manner of the collision was rear-ended collision, followed by angle, single-vehicle, and sideswipe same direction crashes. Rollover only accounted for $2 \%$ of all crashes. Head-on collisions were few in numbers but had the highest percentage of injury crashes, followed by rear-end collisions, single-vehicle crashes, and angle crashes. The combination of sideswipe collisions had an injury percentage of $12 \%$; however, the injury percentage for the same-direction category was three times higher than the opposite direction.

It was observed that different crash types can follow different trends throughout the day. Rear-end collision seems to be the only category with peak during the darker hours of the day between 6:00 PM to 9:00 PM. Rear-end collision was found to be the dominant manner of collision for FVCs under dark (not-lighted) conditions, comprising $65 \%$ of this category, while only accounting for $15.6 \%$ of the crashes in daylight. Specifically, in dark conditions, it is approximately 4 times more likely for the farm vehicle to be hit from behind by other motorists than it is during daylight, which indicates the importance of improving the visibility, lighting and marking of farm vehicles.

A review of the law and regulation in Delaware showed that farm vehicles are currently exempt from most of the requirements regarding the registration, operation, and safety, as well as, size and weight restrictions. Although newly manufactured farm vehicles are equipped with ASABE (American Society of Agricultural and Biological Engineers) standards, the older models can still legally travel on the roads without sufficient lighting and marking, or basic safety equipment such as seatbelt and Roll-over protective structures (ROPS). Further, there is no special license or training required for the operation of farm vehicles. The misuse of the SMV (Slow Moving Vehicle) emblem also seemed to be another common issue throughout the state which indicates the lack of public knowledge of the meaning and correct use of this emblem.

\section{Acknowledgements}

The authors would like to express their gratitude to the Delaware Department of Transportation and the Delaware Center for Transportation for supporting this project. In particular, all the assistance received from Mr. Scott Neidert who served as the project manager is much appreciated. 


\section{Conflicts of Interest}

The authors declare no conflicts of interest regarding the publication of this paper.

\section{References}

[1] United States Department of Agriculture (2019) 2017 Census of Agriculture: Summary and State Data. Geographic Area Series AC-17-A-51.

[2] Shortridge, D. (2015) DelDOT and Delaware Dept. of Agriculture Urge Drivers to Be Cautious When Sharing the Road with Farm Equipment-State of Delaware News. Delaware News, 21 October. https://news.delaware.gov/2015/10/20/deldot-and-delaware-dept-of-agriculture-urg e-drivers-to-be-cautious-when-sharing-the-road-with-farm-equipment

[3] Costello, T.M., Schulman, M.D. and Luginbuhl, R.C. (2003) Understanding the Public Health Impacts of Farm Vehicle Public Road Crashes in North Carolina. Journal of Agricultural Safety and Health, 9, 19-32. https://doi.org/10.13031/2013.12347

[4] Hanna, H.M., Schwab, C.V., Lehtola, C.J. and Steffen, R.W. (1997) Evaluation of Tractor and Grain Wagon Safety Marking at Selected Commercial Iowa Grain Elevators. Journal of Agricultural Safety and Health, 3, 91. https://doi.org/10.13031/2013.17749

[5] Jaarsma, C.F. and de Vries, J.R. (2014) Agricultural Vehicles and Rural Road Safety: Tackling a Persistent Problem. Traffic Injury Prevention, 15, 94-101. https://doi.org/10.1080/15389588.2013.789135

[6] Scott, E., Hirabayashi, L., Jones, N., Krupa, N. and Jenkins, P. (2019) Characteristics of Agriculture Related Motor Vehicle Crashes in Rural New York State. Journal of Agromedicine, 25, 173-178. https://doi.org/10.1080/1059924X.2019.1623143

[7] ANSR (2014) Ficha temática "Veículos agrícolas". http://www.ansr.pt/Estatisticas/FichasTematicas

[8] Wardle, N.J. (1961) Tractors + Traffic = Trouble. Iowa Farm Science, 15, Article 4. https://lib.dr.iastate.edu/cgi/viewcontent.cgi?article $=1142 \&$ context=farmscience

[9] Volpe, J.A. (1971) Agricultural Tractor Safety on Public Roads and Farms: A Report to the Congress.

[10] Harland, K.K., Greenan, M. and Ramirez, M. (2014) Not Just a Rural Occurrence: Differences in Agricultural Equipment Crash Characteristics by Rural-Urban Crash Site and Proximity to Town. Accident Analysis and Prevention, 70, 8-13. https://doi.org/10.1016/j.aap.2014.02.013

[11] Gkritza, K., Kinzenbaw, C.R., Hallmark, S. and Hawkins, N. (2010) An Empirical Analysis of Farm Vehicle Crash Injury Severities on Iowa's Public Road System. Accident Analysis and Prevention, 42, 1392-1397. https://doi.org/10.1016/j.aap.2010.03.003

[12] Greenan, M., Toussaint, M., Peek-Asa, C., Rohlman, D. and Ramirez, M.R. (2016) The Effects of Roadway Characteristics on Farm Equipment Crashes: A Geographic Information Systems Approach. Injury Epidemiology, 3, Article No. 31. https://doi.org/10.1186/s40621-016-0096-1

[13] Hughes, R. and Rodgman, E. (2000) Crashes Involving Farm Tractors and Other Farm Vehicles/Equipment in North Carolina 1995-1999. University of North Carolina Highway Safety Research Center, Chapel Hill. https://rosap.ntl.bts.gov/view/dot/4790 
[14] Lacy, J.K., Hunter, W. and Huang, H. (2003) Study of Farm Vehicle Crashes in North Carolina. Transportation Research Record: Journal of the Transportation Research Board, 1840, 178-185. https://doi.org/10.3141/1840-20

[15] Glascock, L.A., Bean, T.L., Wood, R.K., Carpenter, T.G. and Holmes, R.G. (1995) A Summary of Roadway Accidents Involving Agricultural Machinery. Journal of Agricultural Safety and Health, 1, 93-104. https://doi.org/10.13031/2013.19457

[16] Delaware State Police (2005-2019) Traffic Annual Statistical Report. https://dsp.delaware.gov/reports

[17] Zeigenfuss, L. (2019) Maryland Rural Road Safety Study: An Analysis of Farm Vehicle/Farm Equipment-Related Accidents in the State of Maryland. Maryland Soybean Board, Salisbury.

https://www.mdsoy.com/wp-content/uploads/2019/07/MD-Rural-Road-Safety-Stud y.pdf

[18] Census of Agriculture 2017 Delaware.

[19] U.C. Bureau (2010) Census Urban and Rural Classification and Urban Area Criteria.

https://www.census.gov/programs-surveys/geography/guidance/geo-areas/urban-ru ral/2010-urban-rural.html

[20] National Highway Traffic Safety Administration and U.S. Department of Transportation (2019) 2017 Data: Rural/Urban Comparison.

https://crashstats.nhtsa.dot.gov/Api/Public/ViewPublication/812741\#: :text=Of\%20 the\%2019\%2C038\%20urban\%20traffic,killed\%20in\%20speeding\%2D\%20related\%2 0crashes.\&text=Rural\%20alcohol\%2Dimpaired\%2Ddriving\%20fatalities,2008\%20to $\% 205 \% 2 \mathrm{C} 702 \% 20 \mathrm{in} \% 202017$

[21] Department of Transportation, the State of Delaware. Home-Delaware Department of Transportation-State of Delaware. https://deldot.gov 